\title{
THE ARCHES OF THE FEET OF COMPETITORS IN SELECTED SPORTING DISCIPLINES
}

\author{
MAŁGORZATA LICHOTA ${ }^{1}$, MAGDALENA PLANDOWSKA², PATRYCJUSZ MIL ${ }^{3}$ \\ The Josef Pilsudski University of Physical Education in Warsaw, \\ Faculty of Physical Education and Sport in Biała Podlaska, Chair of Physical Education, \\ ${ }^{1}$ Department of Correction and Compensation, \\ ${ }^{2}$ Department of Theory and Methodology of Physical Education, \\ ${ }^{3}$ Waterworld Centre "Aquatic Fun", Warsaw
}

\author{
Mailing address: Małgorzata Lichota, Faculty of Physical Education and Sport, \\ 2 Akademicka Street, 21-500 Biała Podlaska, tel.: +48 83 3428752, fax: +48 83 3428800, \\ e-mail: malgorzata.lichota@awf-bp.edu.pl
}

\begin{abstract}
Introduction. The human foot is an important and individual static-dynamic part of the movement apparatus. Physical activity is one of the many factors which has an impact on the arch of the foot, and specific sporting disciplines affect the morphological construction and active efficiency of the foot to differing degrees. The aim of this study was to evaluate the foot-arches of competitors training in the disciplines of athletics, handball, volleyball and taekwon-do, and to demonstrate the differences in the arching of the foot, depending on the discipline of the participant. Material and methods. Observation of a group of 46 student-competitors at the sports club of the Academic Sports Association (ASA) of the Faculty of Physical Education and Sport in Biała Podlaska, training in handball, volleyball, athletics and taekwon-do. Using information from plantograms, obtained using a podoscope, the following were analyzed: Wejsflog's indicator, the position of the big toe (hallux) - angle $\alpha$; the position of toe $\mathrm{V}-$ angle $\beta$; the position of the heel - angle $\gamma$. Results. The values given by Wejsflog's indicator show the presence of an asymmetry in the arch of the right foot compared to that of the left foot. The reason for this, according to Demczuk-Włodarczyk and Bieć [1] may be the type of surface on which training is conducted. The authors demonstrate that fallen arches are less common in practitioners of taekwon-do, who usually train on an elastic mat, which confirms the results of earlier research conducted on competitors at the Academic Sports Association of the Faculty of Physical Education and Sport in Biała Podlaska. Conclusions. The occurrence of an abnormal formation of the arches that make up the arch of the foot, and of asymmetry in the arch between the left and right feet observed in the sample, shows the necessity of devoting greater attention to compensatory exercises that strengthen the short muscles of the foot and the muscles of the calf in the training process, in order to make up for frequently unbalanced strain.
\end{abstract}

Key words: arches of the foot, Wejsflog's indicator, sport, BMI

\section{Introduction}

The human foot is an important and individual staticdynamic part of the movement apparatus. On the one hand, it provides support and in static conditions allows the body to balance in one position in space. It is one of the most active parts of the human body and more often than other parts is subject to extreme strain, as it carries the weight of the body, as well as, often, additional loads held or carried by a human being. On the other hand, however, the foot plays an important role in the mechanics of walking, as an element of posture that maintains a direct connection with the floor in a stationery position and in locomotive movement. It also accounts for amortization, protecting the spine and skull against tiny shocks while in motion.

The foot consists of three sections: the back - the bones of the tarsus - the middle - bones of the metatarsus - and front bones of the toes. The tarsus is made up of seven bones: the talus, the calcaneus, the cuboid, three cuneiform bones (the medial, intermediate and lateral) and the navicular. The metatarsus is made up of five long bones of small dimensions, and for each of them it is possible to identify a posterior (articulating proximally with the bones of the tarsus), dorsal and anterior section (with a ligament surface for the corresponding toe).

The foot has its own external and internal architecture, ensuring the possibility of supporting the weight of the whole body and fulfilling the function of a mechanism of motion. The external architecture of the foot is created by a system of longitudinal arches (medial and lateral) and transverse arches (anterior - peripheral and posterior), which make up a kind of suspension that spreads to support a load, and returns to its original state thanks to its individual characteristics. Strictly speaking, the weight of the body is spread over the heel bone and the anterior parts of the metatarsal bones I and V. The heel bone, being one of the densest bones of the tarsus, is strengthened by the strongest muscle, whereas the metatarsus makes up the most flexible part of the foot.

The arches have a major effect on the efficacy of the foot: the longitudinal metatarsal and the transverse anterior are the most flexible and dynamic elements, while the longitudinal lateral and the transverse posterior fulfill static functions. The toes fulfill an equally essential role for the correct functioning of the foot. Their individual form allows for the effective functioning 
of the remaining segments of the foot. In cases where a heavy load is present the toes adhere to the ground, and their strong adherence while walking relieves weight from the anterior bones of the metatarsus.

The foot of a small child has an abundant layer of fat and lacks the arches of the sole. The arches develop in the $3^{\text {rd }}$ or $4^{\text {th }}$ year. The most important period for the formation of the foot is the pre-school period and the early school years. At the age of 6-7, the longitudinal and transverse arches become clearly visible. At the age of 12-14, the foot acquires a form similar to that of an adult, and the final formation of the bones is complete by around the $18^{\text {th }}$ year $[4,5]$.

The human foot, even more than the other sections of the organ of motion, is susceptible to various types of influence from environmental factors, which cause many deviations from its correct structure. Apart from genetic factors and diseases, numerous environmental stimuli can affect the foot's growth and its efficiency in constructive or destructive ways. One of the external factors is the weight of the body. The type of surface with which the foot comes into contact has some significance, as does the quality and type of shoe, the type of activities undertaken and the weight that the feet must bear. Other factors that cause changes in the region of the foot are: diseases of the circulatory system, inflammations, diseases of the bones, incorrect footwear (often connected to fashion), lack of attention to the hygiene and protection of the legs, pregnancy $[4,6,7,8,9]$.

One of the main factors with an impact on the arches of the foot is physical activity, which shapes the developmental processes of children and young people to a significant degree [10]. The specifics of a movement performed, its duration and the intensity of effort all carry significance. Individual sporting disciplines have different levels of impact on the morphological structure and active efficiency of the foot. The state of the feet of sportsmen depends significantly on the type of effort and the weight of the load carried, which differs in different disciplines, and depends on the type of surface on which training and competition are conducted. The sportsman's ability to move depends to a significant degree on the efficacy of the feet. The morphology of the feet and its relation to risk factors in sport, as well as trauma, are the subject of interest of numerous researchers [1, $7,11,12,13,14,15,16,17,18,19,20,21]$.

The aim of the this study was to analyze the state of the footarches of competitors training in the fields of athletics, handball, volleyball and taekwon-do, and to show any differences in the arches of the foot contingent on the discipline of the athlete.

\section{Material and methods}

Observation of a group of 46 student-competitors at the sports club of the Academic Sporting Union (AZS) of the Faculty of Physical Education and Sport in Biała Podlaska, training in the field of athletics (LA $n=9$ ), handball (PR $n=16)$, volleyball (PS $n=12$ ), and taekwon-do ( $\mathrm{T} n=9)$. The competitors had trained for at least five years and were training at an intensity of 1.5 hours, five or six times per week.

In order to examine the state of the arches a computer podoscope from the firm Posmed was used [22]. This is a non-interventional measurement and diagnostic device consisting of a podoscope with a camera connected to a computer, which registers photographs of the sole of the foot, and a computer program which allows for analysis of the parameters of the foot. The person under investigation took up a relaxed standing position, barefoot, with the weight of his or her own body equally distributed across both feet, on a reinforced plate on an aluminium frame of a height of $0.5 \mathrm{~m}$. The resulting image was sent to the computer and recorded using the computer program EIPodo, version 2.1 from the firm Posmed [23]. The shape of the arch and the positioning of the toes were determined by means of anthropometrical points marked on the foot, and visible on the recorded image. The plantograms were assessed using Wejsflog's method [24], calculating the indicator 'Ww' from the following example (Fig. 1):

$$
\mathrm{Ww}=\left(\mathrm{xx}^{\prime} / \mathbf{y} \mathbf{y}^{\prime}\right) \mathbf{x} 100
$$
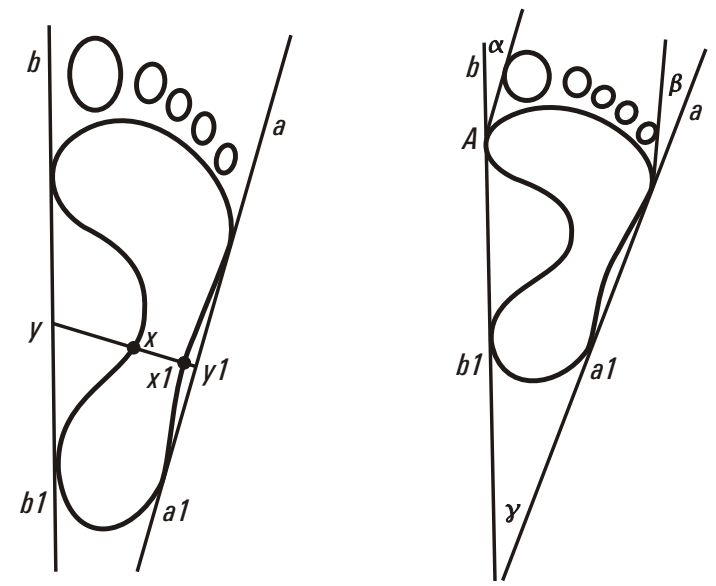

Key:

$\mathrm{xx}^{\prime}$ - width of the tarsal band

yy' - full width of the tarsus

$\alpha$ - angle of the hallux

$\beta$ - angle of toe $\mathrm{V}$

$\gamma$ - angle of the heel

Figure 1. Criteria of assessment of the arches of the foot on the basis of plantograms, analysed using Wejsflog's indicator

Based on Wejsflog's system, taken from Zeyland-Malawka [25], it was assumed that the value given by the indicator of the arch, defining the width of the tarsal band as a percentage, can be used to classify the feet as follows: 0-27 hollow foot; 28-38 correctly arched foot; 39-50 first degree flat foot; 51-66 second degree flat foot; 67-100 third degree flat foot; over 100 fourth degree flat foot.

In the study, the angles of the foot were also analyzed: the position of the big toe (hallux) (angle $\alpha$ ), the position of the fifth toe (angle $\beta$ ), the position of the heel (angle $\gamma$ ). On the basis of Wejsflog's indications [24] the following guidelines were used: $0^{\circ}-9^{\circ}$ as the norm for the angle of the valgus of the big toe and the varus of the fifth toe; $15^{\circ}-18^{\circ}$ as the norm for the angle of the heel.

Measurements were taken in the morning.

Additionally, measurements of the height and weight of the body were taken, using an electronic scale with a heightmeasurement function accurate to $0.5 \mathrm{~cm}$ (height) and $0,1 \mathrm{~kg}$ (weight). These measurements served to calculate BMI, which served to indicate the proportion of weight to height among the people in the research sample.

The information obtained was processed statistically, taking into account the differences between the right and left feet. The following basic statistical measures were applied to the material collected by the researcher: the arithmetical mean $(\bar{x})$, standard deviation (SD), standard error (SE), the spread of features analyzed (min-max) and the frequency with which they occurred (\%). With the aim of ascertaining the statistical significance of the difference, the t-Student test was used. The level of statistical significance of the difference was taken to be $<0.05$ [26]. For the statistical analyses the program Excel from the Microsoft Office for Windows package was used. 


\section{Results}

The average values for the height of the body, the weight of the body and BMI, obtained for the competitors in the fields of athletics, handball, volleyball and taekwon-do, are shown in Figure 2.

The dimensions of the body of the students under scrutiny ranged from $169.0 \mathrm{~cm}$ to $203.0 \mathrm{~cm}$ (height) and $68.0 \mathrm{~kg}$ to $105.2 \mathrm{~kg}$ (weight). The values of the BMI indicator were within the range 18.8-32.1. A BMI value falling between 20 and $25 \mathrm{~kg}$ per $\mathrm{m}^{2}$, and therefore the normal proportion of weight to height, was observed in 34 students (73.91\%), i.e. in all athletics competitors, $43.8 \%$ of the handball players, $83,3 \%$ of the volleyball players, and $88.9 \%$ of the taekwon-do competitors. A greater body mass quota (BMI 25-30) was observed in the case of 11 students $(23,91 \%)$, i.e. in $50 \%$ of the handball players, $15.38 \%$ of the volleyball players and in one taekwon-do competitor. In the case of one handball player (2.17\%), the BMI quota was above $30 \mathrm{~kg} / \mathrm{m}^{2}$.

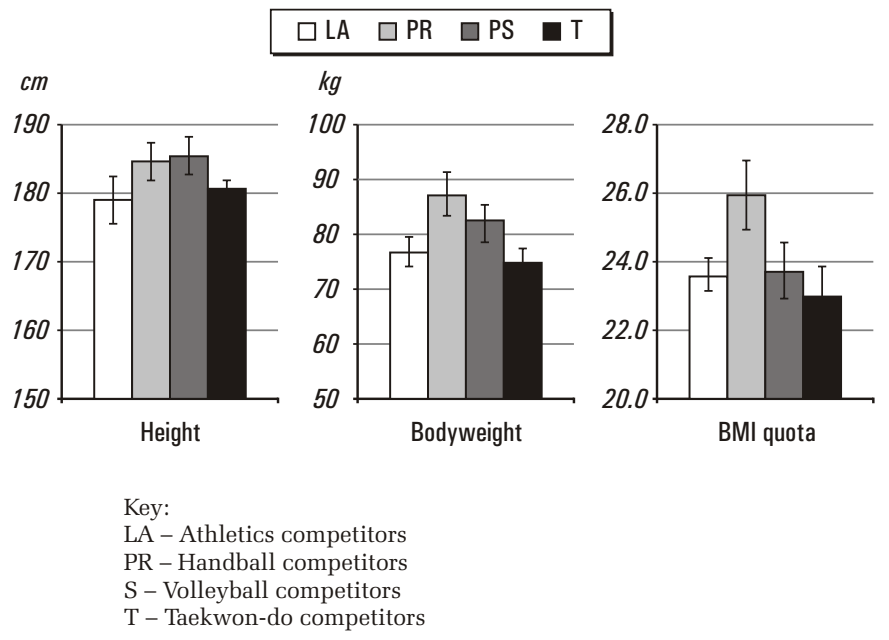

Figure 2. Average values for height, bodyweight, and BMI quota for competitors in different sporting disciplines

The differences observed in height and bodyweight, and in the BMI quotas obtained were statistically insignificant.

The average values of the indicator Ww were grouped around 40.54 for the left foot and 35.29 for the right foot. The highest values of the Wejsflog's indicator were recorded in the case of a handball player: 43.08 for the left foot and 39.88 for the right foot. The lowest values were recorded in the case of a taekwon-do competitor, namely 33.84 for the left foot and 39.88 for the right foot (Fig. 3).

Analysis of the arches of the foot according to Wejsflog's indicator showed a variation in the arches depending on which foot was observed, right or left, but did not show variation between the groups. Higher values were established in the case of the left than the right foot for athletes of each discipline

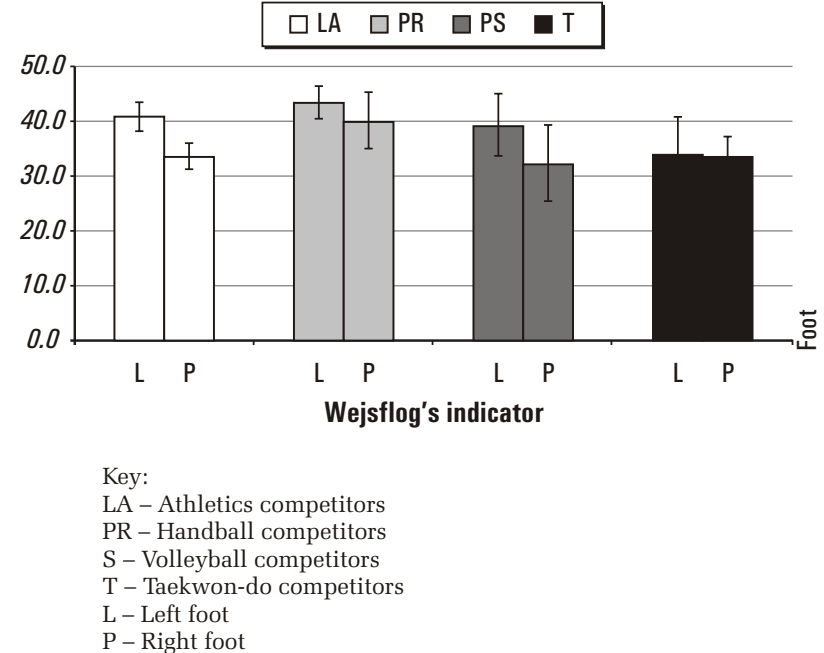

Figure 3. Average values of the Wejsflog's indicator (Ww) amongst the sample of competitors

Taking into account the assessment criteria of the Wejsflog's indicator (Ww), alongside Zeyland-Malawka's adjustments [23] it was established that approximately $30 \%$ of those analyzed had the normal foot arch. This situation was observed most frequently in relation to taekwon-do competitors $(44.4 \%$ of left feet and $56.4 \%$ of right feet), noticeably less frequently amongst handball players (37.5\% and $25 \%$ respectively), and least frequently amongst athletics competitors $(11.1 \%$ and $22.2 \%$ respectively). An insignificant lowering of the longitudinal arches of the feet, described as first degree flat footedness, appeared in the case of more than a quarter of competitors, most commonly amongst athletics competitors and volleyball players. Second degree flat-footedness was observed in one in five of the competitors, primarily those training in handball. High arches, leading to hollow feet were found in the case of approximately $25 \%$ of the competitors. The greatest number with this shape of foot was found amongst volleyball players, athletics competitors and taekwon-do competitors, and it was found to be more common in the right foot than the left (Fig. 4).

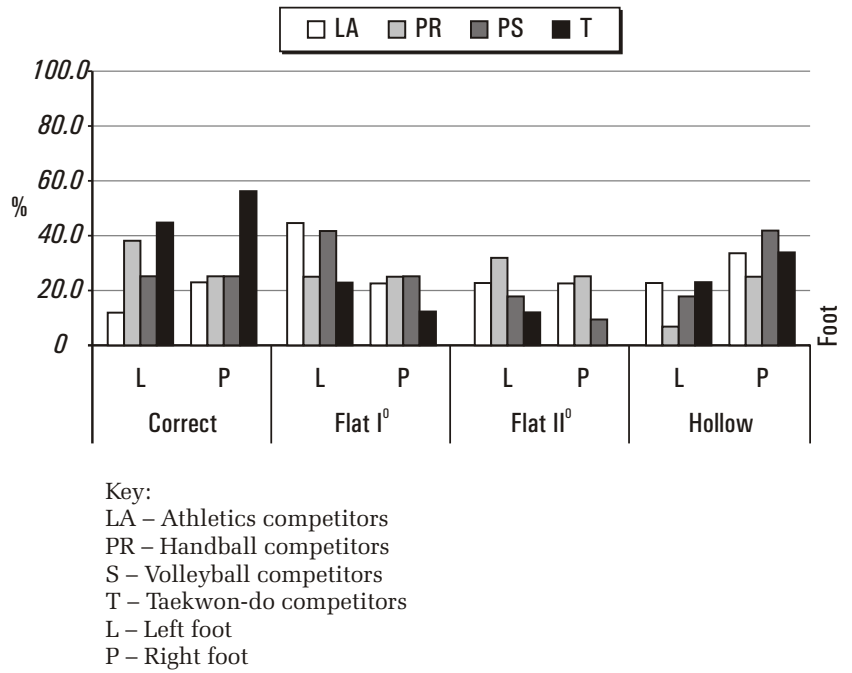

Figure 4. The typical arch of the foot amongst the sample of competitors according to Wejsflog's indicator 
In a general assessment of the arches of the foot the angle measurements were also taken, describing the position of the big toe (hallux) (angle $\alpha$ ), the position of the fifth toe (angle $\beta$ ), the position of the heel (angle $\gamma$ ).

The average values for the angle $\alpha$ found amongst the majority of competitors showed a correct positioning of the big toe within the range $0^{\circ}$ to $9^{\circ}$, with the exception of the left feet of handball players, with a variation of $13.9^{\circ}$ to $13.3^{\circ}$, and athletics competitors, with a variation of $8.5^{\circ}$ to $10.0^{\circ}$.

Angle $\beta$, referring to the position of toe $\mathrm{V}$, showed average values above 15 degrees, indicating a valgus position of the smallest toe, with the exception of the left feet of taekwon-do competitors, whose average value remained below 10 degrees.

The most stable was the angle of the position of the heel (angle $\gamma$ ), with average values falling between $15^{\circ}$ and $18^{\circ}$, defined as the correct position of the back of the foot (Fig. 5).

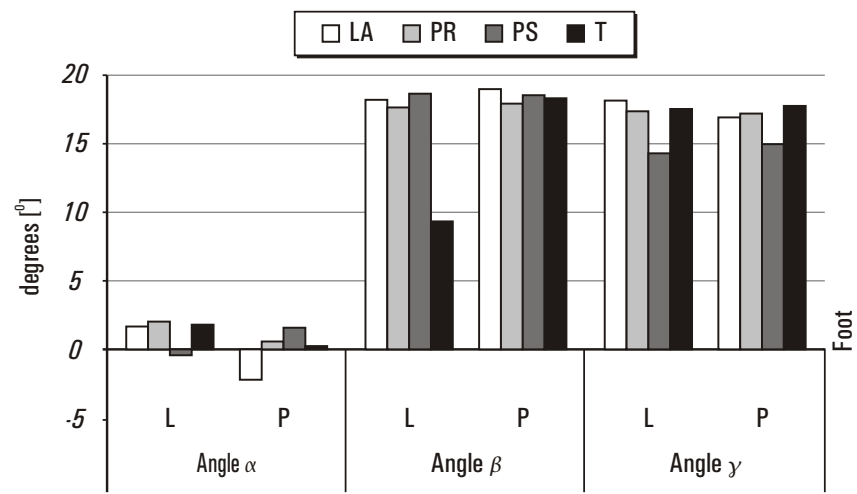

Key:

LA - Athletics competitors

PR - Handball competitors

S - Volleyball competitors

$\mathrm{T}$ - Taekwon-do competitors

L - Left foot

P - Right foot

Figure 5. Average values for angle $\alpha$ - the position of the hallux, angle $\beta$ - the position of toe $\mathrm{V}$ and angle $\gamma$ - the position of the heel in competitors of different sporting disciplines

A more detailed analysis of the state of the arches of the foot amongst competitors of the chosen sporting disciplines showed that approximately $70 \%$ of the sample had an abnormal footarch. Flattening of the longitudinal arches occurred more frequently in the left foot amongst practitioners of athletics and handball, whereas hollow feet were found in the case of the right foot, particularly amongst volleyball players.

An incorrect positioning of the big toe was noted in nearly $50 \%$ of the sample of competitors. Most frequently a varus positioning was found, i.e. amongst $61 \%$ of athletics competitors, $36 \%$ of handball players, $51 \%$ of volleyball players and $33 \%$ of taekwon-do competitors. Amongst all those examined this abnormal positioning was observed more frequently in the right foot. A valgus positioning of the big toe was found in the case of less than $10 \%$ of the sample (Fig. 6).

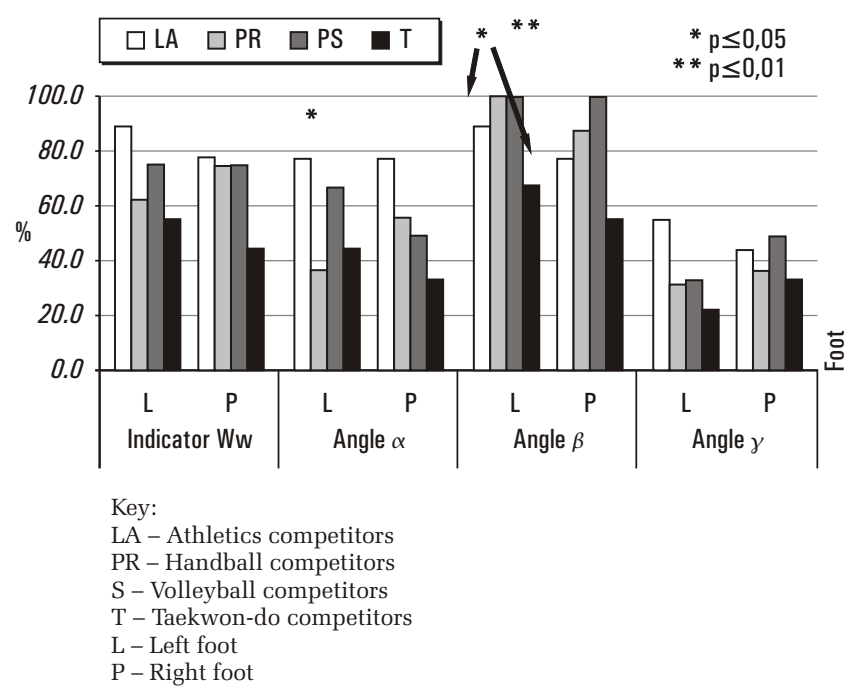

Figure 6. Abnormal foot-arches according to Wejsflog's indicator, and the position of the hallux - angle $\alpha$, toe $\mathrm{V}-$ angle $\beta$ and the heel - angle $\gamma$ of the sample of competitors

The angle of the position of toe $\mathrm{V}$ amongst the majority of the competitors (93\% of right feet and $85 \%$ of left feet) exceeded the upper limit of the norm $\left(9^{\circ}\right)$, which is evidence of a valgus positioning. A varus positioning of the smallest toe was found only in the case of the left feet of handball players (12.5\%) and taekwon-do players (11.1\%).

Abnormal positioning of the heel bone was noted in the case of approximately $50 \%$ of the athletics competitors, $35 \%$ of the handball players, $42 \%$ of the volleyball players and $27 \%$ of the taekwon-do competitors. Abnormal positioning at the back of the foot applied more commonly to the right foot.

The abnormality observed in the construction of the feet of competitors in the selected sporting disciplines was statistically significant only in the case of left feet and in relation to the position of toe $\mathrm{V}$ and the big toe (hallux).

Analysis of the foot-arches using the Wejsflog's method showed the frequent occurrence of abnormalities in the shape of the longitudinal arches, the position of the big toe, toe $\mathrm{V}$ and the heel. Using the criteria set out by Zeyland-Malawka it is necessary to stress that a decisive majority of the competitors being assessed had an abnormal foot shape, slightly more frequently found in the left foot (76\%) than the right $(71.7 \%)$. Moreover, a considerable asymmetry in the arches between the right and left foot became evident.

\section{Discussion}

A review of academic findings thus far shows that the subject of the formation of the sole amongst sportsmen has been researched most frequently in relation to martial arts $[1,14,15$, $19,20,21)$, athletics competitors [7, 11, 27] and basketball players [17]. Moreover, the results obtained by past research projects are often incomparable, because they employ different methods or measurement techniques. As a result of this, all information relating to the issues investigated in this study is valuable, complementing publications on the subject of the foot-arches of sportsmen.

The researcher's own investigations based on analysis of the foot-arches using Wejsflog's method show the frequent occurrence of abnormalities in the arches of the foot. A decisive majority of sportsmen have abnormally shaped feet and this is slightly more frequent in the left $(76 \%)$ than the right foot 
(71.7\%). Moreover, the analysis showed an insignificant asymmetry between the right and left feet in relation to the footarches.

Research on the variability of foot-arches amongst practitioners of different sporting disciplines has already been carried out by Niżankowski and Wanke [12]. The results of investigations taking into account sporting disciplines like boxing, swimming, volleyball, basketball and ballet showed that the worst longitudinal arches were found amongst boxers and swimmers, and the best amongst basketball players and professional ballet dancers. Socha [13], in her turn, observed high values for the Clarke's angle amongst swimmers, and a greater tendency towards hollow feet than amongst other sportsmen. Nadolska-Ćwikła [16], analyzing the foot-arches of boys in sports teams, stated that the best values for the Clarke's angle were found in swimmers, then basketball players and volleyball players. The author observed the best formation of the transverse arch amongst volleyball players, and the worst amongst swimmers.

Kuraś [11] assessed the changes in the foot-arches of athletics practitioners and stated that amongst middle- and long-distance athletes, it is possible to observe a lowering of values of the Clarke's angle, connected to the effort of training. Stawczyk [27] claimed that the jump foot of long-jumpers and highjumpers shows a lowering of the arch in contrast with the opposite foot. Investigations into the foot-arches of young practitioners of athletics (16-17 year-olds) (based on Clarke's angle and the Godunow-Sztriter's indicator) carried out by Gradek et al. [7] showed that in spite of several years training, a lowering of the longitudinal arch was observed in only rare cases. In the light of assessments of the position of the heel bone and lengthbreadth indicators, the majority of long-jumpers had a normal transverse arch, whereas high jumpers most commonly had a raised foot-arch.

The author's own research, carried out amongst competitors in the sporting disciplines analyzed showed that the taekwondo competitors typically had the best foot-arches. Systematic training on a soft surface (mat) certainly has a beneficial effect on the foot-arches, as evidenced by research on martial arts competitors conducted by other authors.

Plantographic investigations on the world's best wrestlers conducted by Ślężyński and Dębska [14] using Clarke's angle showed that the people under scrutiny typically had a high longitudinal arch. Furthermore, the authors demonstrated that the average values for the angle of the heel and for the valgus hallux are considerably higher than the norm in certain weight categories, which is linked to the greater than average width of the foot. Nadolska-Ćwikła [15], conducting research on wrestlers of the Polish national team, also demonstrated that the feet of the wrestlers under investigation typically showed a good arch (based on assessment of the Clarke's angle) with a low percentage of subjects with a clear case of flatfoot. The normal morphological construction of the longitudinal arch of martial arts practitioners (based on the measurements and assessment of the height of five longitudinal arches) support the results published by Demczuk-Włodarczyk and Bieć [1]. Investigations of the intensity with which particular structures adhere to the floor, and the size of the angle of the big toe, showed, however, a disorder of the anterior segments of the foot - the transverse arch and the front load-bearing zone. In the group of Judo competitors investigated by Boguszewska [19], the longitudinal arch (based on the Clarke's angle) and the transverse arch (based on the designated angle of the heel), measured in a load-bearing situation, fell within the boundaries of the norm, which is evidence of a normal arch. Significant differences between the arches of left and right feet were not found. A similar observation was made by Andrzejewska et al. [20]. Analyzing the morphological construction of the feet of judo competitors, based on the Clarke's angle, the authors showed that the competitors typically showed a normal longitudinal arch, although they observed slightly worse results for the heavyweight group, leading the authors to the conclusion that the greater pressure resulting from a greater body weight flattens the longitudinal arches of the foot. Selected measurements of the construction of the feet of karate competitors, using the Wejsflog's indicator and the Clarke's angle, were also assessed by Trocińska [21]. The results of the investigation showed that the majority of the people under scrutiny had a normal longitudinal arch, although this was more common in men than in women. The author also observed a minor asymmetry in the construction of the arches of the right and left foot.

\section{Conclusions}

- The feet of the sample of competitors typically showed an abnormal shape in both the longitudinal and transverse arches.

- Amongst the competitors under scrutiny, the practitioners of taekwon-do had the best arches, whereas the practitioners of athletics had the worst.

- Differences in the arches of the right and left feet are the result not only of dynamic and functional asymmetry, but also of considerable, often one-sided loads, linked to a particular sporting discipline. The above fact shows the necessity of devoting greater attention to exercises that strengthen the short muscles of the foot and the muscles of the calf during the training process.

\section{Literature}

1. Demczuk-Włodarczyk E., Bieć E. (2002). The morphological construction of the feet of martial arts competitors. Fizjoterapia 3-4, 37-42. [in Polish]

2. Dziak A. (1973). The Anatomy of the Foot. Chorzów: PWSZ. [in Polish]

3. Bochenek A., Reicher M. (1990). Human Anatomy. vol. I. Warszawa: PZWL. [in Polish]

4. Demczuk-Włodarczyk E. (2003). The Construction of the $\mathrm{Hu}$ man Foot in The Period of Progressive Development. Wrocław: AWF. [in Polish]

5. Kutzner-Kozińska M. (2008). The Process of Correcting Faults of Posture. Warszawa: AWF. [in Polish]

6. Malina H. (1996). Faults of the Lower Limbs. Corrective Procedures. Kraków: Firma Handlowo-Usługowa Kasper. [in Polish]

7. Gradek J., Mleczko M., Bora P. (2004). The arches of the foot in young athletes. Wychowanie Fizyczne i Zdrowotne 67, 11-14. [in Polish]

8. Villaroya M.A., Esquivel J.M., Toma's C., Buenafe A., Moreno L. (2007). Foot structure in overweight and obese children. International Journal of Pediatric Obesity 17, 1-7.

9. Mikołajczyk E., Jankowicz-Szymańska J. (2010). The influence of weight gain on the arches of the foot and the formation of the limbs in seven-year-olds. Fizjoterapia 18(2), 10-20. [in Polish]

10. Furgał W., Adamczyk A. (2008). The formation of the arches of the foot in children dependent on the level of physical activity. Medycyna sportowa 5(6), Vol. 24, 311-317. [in Polish]

11. Kuraś Z. (1958). A functional investigation of the foot in middle- and long-distance athletes from Academic Sports Association in Warsaw. Kultura Fizyczna 8, 567-574. [in Polish] 
12. Niżankowski Cz., Wanke A. (1967). Variation in the arches of the foot of competitors in selected sporting disciplines. Rozprawy Naukowe WSWF Wrocław 14, 209-215. [in Polish]

13. Socha O. (1970). The construction and function of the feet of swimmers and non-swimmers. Rozprawy Naukowe WSWF Wrocław 8, 61-88. [in Polish]

14. Ślężyński J., Dębska H. (1977). Plantographic research on the world's top wrestlers. Wychowanie Fizyczne i Sport 1, 75-84. [in Polish]

15. Nadolska-Ćwikła I. (1998). The arches of the foot amongst wrestlers and the effects of training. In D. Umiastowska (Ed.), Physical activity at different ages. III Scientific Conference, 4-5 January 1997. Scientific Materials no 3 (pp. 43-46). Szczecin: Wydawnictwo Promocyjne Albatros. [in Polish]

16. Nadolska-Ćwikła I. (2000). The assessment of the footarches of fifteen-year-old boys participant and non-participant in sport. In D. Umiastowska (Ed.), Physical activity at different ages. 2-3 January 1999. Scientific Materials no 5 (pp. 284-289). Szczecin: Wydawnictwo Promocyjne Albatros. [in Polish]

17. Aydog S.T., Demirel H.A., Tetik O., Aydog E., Hascelik Z., Doral M.N. (2004). The sole arch indices of adolescent basketball players. Saudi Medical Journal 25(8), 1100-2.

18. Cain L.E., Nickolson L.L., Adams R.D. (2007). Foot morphology and foot/ankle injury indoor football. Journal of Science and Medicine in Sport 10, 311-319.

19. Boguszewska K. (2008). Assessment of the foot-arches of judo competitors of the Academic Sports Association of the University of Physical Education, Warsaw. Zeszyty Metodyczno-Naukowe AWF w Katowicach 25, 255-262. [in Polish]
20. Andrzejewska J., Burdukiewicz A., Chromik K., Pietraszewska J., Stachoń A. (2010). Morphological structure and characteristics of judo contestants' feet. Acta bio-Optica et Informatica Medica 1(16), 21-24.

21. Trocińska A. (2009). The characteristics of selected aspects of the construction of the foot in women and men doing judo. In B. Marecki (Ed.), Sport and tourism in present life style (pp. 89-95). Poznań: Wydawnictwo AWF w Poznaniu. [in Polish]

22. htts://www.posmed.com.pl

23. Śliwa W., Chromik K. (2005). Faults in body posture and their assessment - training material. Legnica: Wydawnictwo Edytor. [in Polish]

24. Wejsflog G. (1955). Plantoconturographics. Tygodnik Lekarski 10(15), 1670-1677. [in Polish]

25. Zeyland-Malawka E. (1999). Corrective Exercises. Gdańsk: AWF. [in Polish]

26. Stupnicki R. (2000). Biometrics: a Brief Outline. Warszawa: Wydawnictwo MARGOS. [in Polish]

27. Stawczyk Z. (1965). Attainable jumps and the arches of the foot. Roczniki Naukowe WSWF Poznań 10, 229-240. [in Polish]

Submitted: April 4, 2013

Accepted: June 7, 2013 